\title{
The effect of oral progesterone for the treatment of abnormal uterine bleeding in women taking warfarin following prosthetic valve replacement
}

\author{
Shafaq Nadeem ${ }^{1}$, Shahid Abbas², \\ Anjum Jalal ${ }^{3}$
}

\begin{abstract}
Objectives: To evaluate the effect of oral progesterone for the treatment of abnormal uterine bleeding in patients taking warfarin after prosthetic valve replacement.

Methods: A total of 85 women of reproductive age, who were on warfarin due to prosthetic valve replacement were enrolled in the study. After detailed evaluation, their menstrual bleeding was quantified using Pictorial Bleeding Evaluation Chart. The patients were then prescribed an oral progesterone (Norethisterone) $5 \mathrm{mg}$ three times daily. The first follow up was done after one-month then at 3-months and at six months. The improvement in PBAC score was recorded at each visit. Data was entered and analyzed using SPSS (version 23.0). The mean \pm Standard Deviation were calculated for quantitative variables while qualitative variables were presented in frequency table. The normality of data was checked using Kolmogorov-Smirnov test. Due lack of normal distribution of data in various groups, the Wilcoxon Sign Rank test was used to test the significance before and after treatment. The p-value of $<0.05$ was taken as statistically significant.

Results: The mean age of the patients was $30.13 \pm 7.69$ years. The mean PBAC score was $162.8 \pm 24.86$ before initiation of treatment while at the end of the treatment it was $105.48 \pm 8.38$. Forty-six (54.1\%) patients had continuous per vaginal bleeding, 33 (38.8\%) had menorrhagia, $4(4.7 \%)$ had inter-menstrual bleeding and $2(2.4 \%)$ had menorrhagia along with polymenorrhea. The mean dose of warfarin taken by the patients was $5.85 \pm 2.69 \mathrm{mg}$. The median parity of the patients was 2 . The Wilcoxon Sign Rank test showed $\mathrm{p}$-value of $<0.00001$ for comparison of the pre-treatment PCBA values with those of one, three and sixmonths after the treatment. The Friedman's test also had a $p$-value of $<0.00001$. This confirmed that the post treatment bleeding was significantly less than pretreatment bleeding.

Conclusion: The warfarin induced abnormal uterine bleeding can be controlled effectively and safely with low dose of oral progesterone.
\end{abstract}

KEYWORDS: Abnormal uterine bleeding, Menorrhagia, Polymenorrhea, Valve replacement, Warfarin induced menorrhagia.

How to cite this:

doi: https://doi.org/10.12669/pjms.35.4.907

Nadeem S, Abbas S, Jalal A. The effect of oral progesterone for the treatment of abnormal uterine bleeding in women taking warfarin following prosthetic valve replacement. Pak J Med Sci. 2019;35(4):887-892.

doi: https://doi.org/10.12669/pjms.35.4.907

This is an Open Access article distributed under the terms of the Creative Commons Attribution License (http://creativecommons.org/licenses/by/3.0), which permits unrestricted use, distribution, and reproduction in any medium, provided the original work is properly cited.

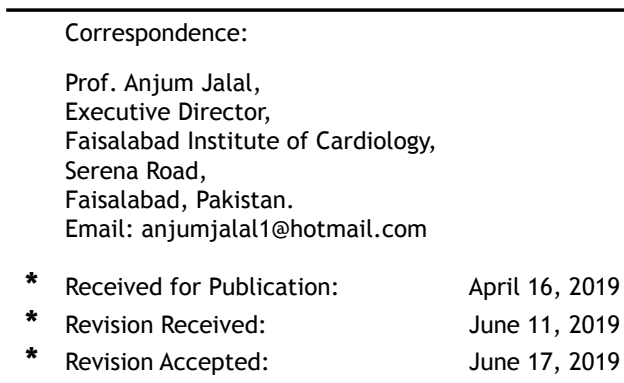

\section{INTRODUCTION}

The literature is scanty about menstrual problems among women on anticoagulants due to cardiac problems. The increased risk of abnormal uterine bleeding with Warfarin is widely established. However, the strategies to deal with this problem are deficient due to lack of coordination between cardiology and gynecology. 
Oral progesterone is as efficacious as that of other hormonal treatment like combined oral contraceptive pills which are relatively less safe in such patients. Sub dermal implants are less effective for menstrual problems while intrauterine devices are invasive mode of treatment with added cost. ${ }^{1}$ Though, intra uterine devices provide a novel approach to tackle with this problem, these cannot be applied to unmarried girls and non-affording women. The safety profile, cost effectiveness and easy availability of oral progesterone can help to reduce various menstrual problems. The aim of this study was to evaluate the effect of oral progesterone for the treatment of abnormal uterine bleeding in patients taking warfarin after prosthetic valve replacement.

\section{METHODS}

This cross sectional descriptive study was conducted at Faisalabad Institute of Cardiology in department of cardiac surgery with the association of consultant gynecologist, cardiologist and cardiac surgeon. A total of 85 women of reproductive age, who had undergone prosthetic valve replacement were enrolled in the study. They were taking warfarin therapy for at least three months along with enteric coated aspirin $75 \mathrm{mg}$ once daily. The INR was kept within the therapeutic range of 2.5 to 3.5 in all patients. At the time of recruitment in the study details of their menstrual cycle including the length, regularity, flow, and abnormal pattern bleeding were assessed using a questionnaire.

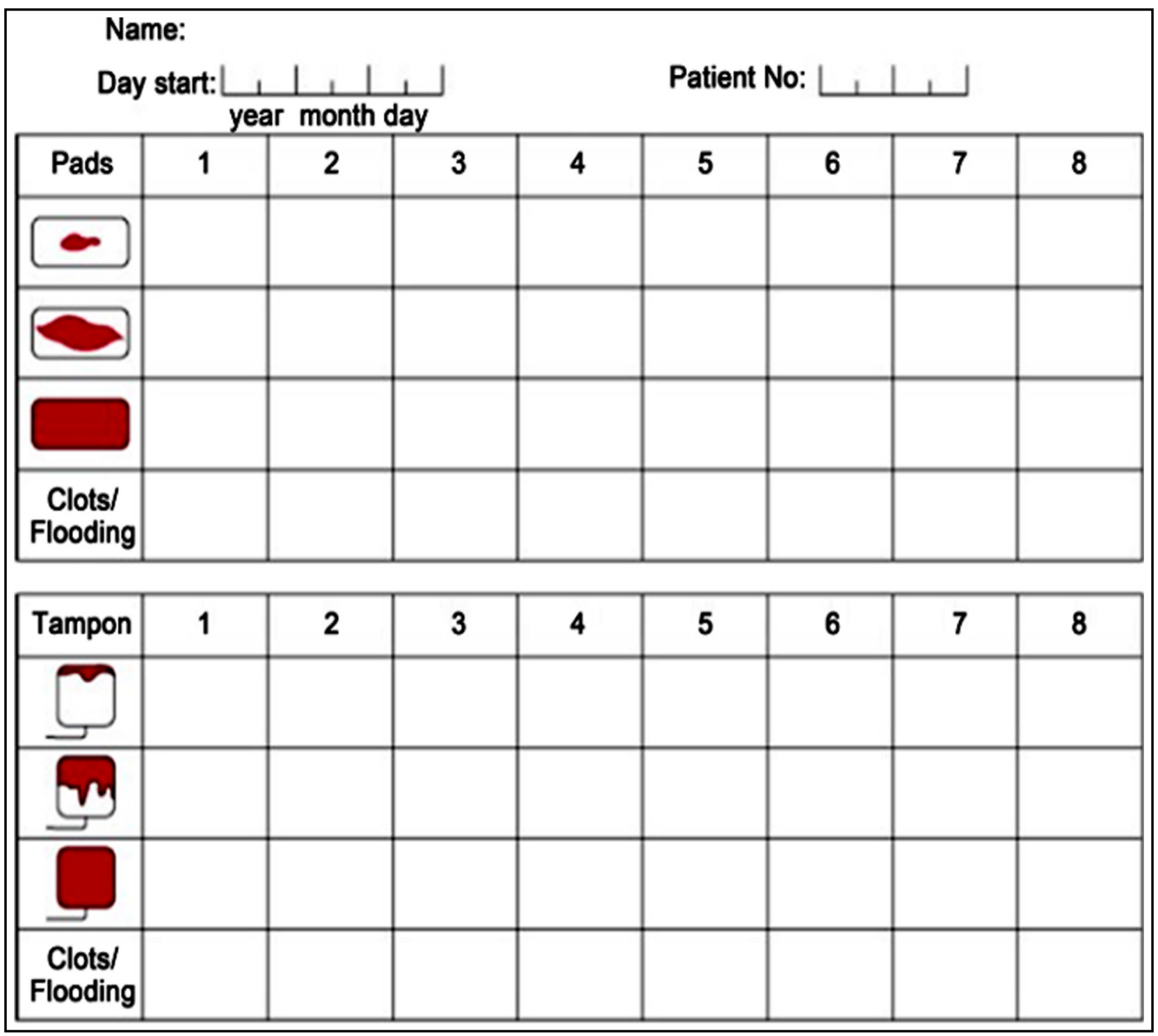

Fig.1: The Pictorial Bleeding Assessment Chart (PBAC). 
Patients were counseled to evaluate the degree of saturation for each sanitary product used during menstruation. During the next menstrual period the bleeding was quantified using score sheet of PBAC (Fig.1). The total number of each type of sanitary product was then listed in the corresponding row during each day of menstruation. Scores on PBAC were assigned for each pad as shown in the Fig.1. A lightly stained pad scored one point, the moderately saturated pad was given five points and completely soaked pad was given 20 points. Moreover, presence of small clot scored one point, whereas large clot scored 5. None of patients used tampons. After noting down the bleeding in preprogesterone menstrual period, the patients were prescribed an oral progesterone (Norethisterone) $5 \mathrm{mg}$ three times daily cyclically. The first follow up was done after one-month then at 3-months and at six months. The quantification was done as described above for these follow-up visits. The patient compliance and sides effects noted by the patients were also recorded. The INR was monitored on the weekly basis and was kept within recommended therapeutic range of 2.5 to 3.5 very strictly.

The improvement in PBAC score was recorded at each visit. Data was entered and analyzed using SPSS (version 23.0). The mean \pm Standard Deviation was calculated for quantitative variables like age, parity, warfarin dose and PBAC score. While qualitative variables like type of prosthetic valve and abnormal menstrual bleeding pattern were presented in frequency table. The normality of data was checked using Kolmogorov-Smirnov test. The Wilcoxon Sign Rank test was used to test the significance before and after treatment due lack of normal distribution of data in various groups detected by the Kolmogorov-Smirnov test. The p-value of $<0.05$ was taken as statistically significant. The Nul hypothesis was defined as: "there is no difference of PBAC score before and after the treatment with progesterone in female patients on warfarin therapy".

\section{RESULTS}

In this study, out of 85 women, the mean age of respondents was $30.13 \pm 7.69$ years. The mean PBAC score was $162.8 \pm 24.86$ before initiation of treatment while at the end of the treatment it was $105.48 \pm$ 8.38. Regarding menstrual bleeding, 46 (54.1\%) had continuous per vaginal bleeding, 33 (38.8\%) had menorrhagia, four $(4.7 \%)$ had inter-menstrual bleeding and two (2.4\%) had menorrhagia along with polymenorrhea. The cardiac surgery profile of the patients is shown in Table-I. Most of them had mitral valve replacement as expected. The mean dose of warfarin taken by the patients was $5.85 \mathrm{mg}$ with standard deviation of $2.69 \mathrm{mg}$ and the median dose of $5 \mathrm{mg}$. The median parity of the patients was two.

Kolmogorov Smirnov test for normality of data was conducted (Table-II). This table shows the values of PBAC in two groups i.e. the pretreatment group and 6-months following the progesterone treatment group, have $\mathrm{p}$-values less than 0.05 and hence are not normally distributed. However, the values of PBAC after one and three months of progesterone treatment are normally distributed. We therefore used non-parametric test to compare the pre-treatment PBAC values with those of one, three and six-months after the treatment, individually using the Wilcoxon Sign Rank test (Table-III). It is obvious that all three comparisons showed highly significant

Table-I: Frequency distribution of various variables.

\begin{tabular}{llcc}
\hline Variable & & Frequency & Percentage (\%) \\
\hline Age (Years) & $<20$ & 10 & 11.8 \\
& $21-30$ & 38 & 44.7 \\
& $31-40$ & 29 & 34.1 \\
\multirow{3}{*}{ Menstrual bleeding } & $41-49$ & 08 & 9.4 \\
& Continuous Per Vaginal & 46 & 54.1 \\
& Menorrhagia & 33 & 38.8 \\
& Inter menstrual Bleeding & 04 & 4.7 \\
\multirow{5}{*}{ Reason for warfarin therapy } & Menorrhagia + Polymenorrhea & 02 & 2.4 \\
& Mitral Valve Replacement & 32 & 37.6 \\
& Double Valve Replacement & 29 & 34.1 \\
& Aortic Valve Replacement & 24 & 28.2 \\
& Total & 85 & 100 \\
\hline
\end{tabular}


Shafaq Nadeem et al.

Table-II: Normality Tests (Kolmogorov Smirnov Test).

\begin{tabular}{lccccc}
\hline & Mean PBAC & Median PBCA & $\begin{array}{c}\text { Stand Deviation } \\
\text { PBCA }\end{array}$ & $\begin{array}{c}\text { K-S } \\
\text { Statistic (D) }\end{array}$ & $\begin{array}{c}\text { K-S } \\
\text {-value }\end{array}$ \\
\hline Pre-Progesterone & 162.80 & 162 & 24.86 & 0.190 & 0.0038 \\
One month Post Progesterone & 125.41 & 123 & 16.02 & 0.128 & 0.1142 \\
3-months Post Progesterone & 110.86 & 110 & 10.10 & 0.118 & 0.1700 \\
6-months Post Progeterone & 105.48 & 103 & 8.38 & 0.147 & 0.0454 \\
\hline
\end{tabular}

Table-III: Comparison of PBAC score before and after treatment with Progesterone using Wilcoxon Sign Rank Test.

\begin{tabular}{lcccc}
\hline Pre - Post Treatment & W Statistics & Mean Difference & Z Statistic & $p$ \\
\hline Pre vs One month Post Progesterone & 0 & 30.8 & -8.0077 & $<0.00001$ \\
Pre vs 3-months Post Progeterone & 2.5 & 48.8 & -7.9967 & $<0.00001$ \\
Pre vs 6-months Post Progesterone & 1 & 50.8 & -8.0033 & $<0.00001$ \\
\hline
\end{tabular}

differences as the $p$-values were $<0.00001$ in each comparison. It is also obvious from the set of data that the PBAC scores were taken from the same individuals at four different times serially. Therefore, we also tested the data with Friedman Test which is a non-parametric variant of ANOVA with repeated measures. The Friedman's $X^{2}$ was 224.05 which has a $p$-value of $<0.00001$. This again proves that the downward trend of PBAC scores after progesterone treatment has a very strong statistical significance.

The pretreatment PBAC and the final post treatment PBAC at 6-months follow-up were also compared in various subgroups of Age, Bleeding Pattern and the Surgical profile. The Wicoxon Sign Rank test for all sub group analyses showed a p-value of $<0.00001$ which is highly significant (Table-IV). This means the progesterone treatment was effective in all subgroups. The patients showed excellent compliance as there were no drop outs from the study. The patient did not report any untoward effects of the progesterone during the study period.

\section{DISCUSSION}

Rheumatic heart disease (RHD) frequently takes a chronic course causing congestive heart failure, stroke, endocarditis and death. ${ }^{2}$ Since early 20th century the incidence of rheumatic heart disease has consistently decreased in developed countries. However, it is still a major cause of morbidity and mortality in young age in the developing countries, including Pakistan..$^{3-5}$ The prevalence of RHD is more in females compared to the males, because women are house bound and therefore are more likely to be affected by overcrowding. ${ }^{6}$

The majority of RHD patients develop valvular heart disease. The mitral valve stenosis with or without incompetence is the most common valvular lesion seen in these patients. ${ }^{7}$ Patients who

Table-IV: Comparison of pretreatment PBAC score with those at six-months post treatment follow-up in different subgroups.

\begin{tabular}{llccc}
\hline Grouping Variables & Subgroups & Mean Rank & Z Statistic & $p$ \\
\hline Age (Years) & $\leq 20$ & 5.50 & -2.805 & $0.005^{*}$ \\
& $21-30$ & 20.00 & -5.360 & $<0.001^{*}$ \\
& $31-40$ & 15.00 & -4.706 & $<0.001^{*}$ \\
\multirow{4}{*}{ Menstrual Bleeding } & $41-49$ & 4.50 & -2.512 & $0.012^{*}$ \\
& Continuous Per Vaginal & 24.00 & -5.896 & $<0.001^{*}$ \\
& Menorrhagia & 17.00 & -5.014 & $<0.001^{*}$ \\
& Inter menstrual Bleeding & 2.5 & -1.826 & 0.068 \\
Treatment & Menorrhagia + Polymenorrhea & 1.50 & -1.342 & 0.180 \\
& MVR & 17.00 & -4.919 & $<0.001^{*}$ \\
& DVR & 15.00 & -4.705 & $<0.001^{*}$ \\
& AVR & 12.50 & -4.287 & $<0.001^{*}$ \\
\hline
\end{tabular}

* Significant Value ( $\mathrm{p}$-value $<0.05)$. 
undergo surgical intervention may have either a bio prosthetic valve replacement or a mechanical valve replacement. ${ }^{8}$ After surgical treatment there is need to initiate vitamin $\mathrm{K}$ receptor antagonist drugs like warfarin in order to prevent thrombus formation of the mechanical valves. Since its discovery in 1940, warfarin has withstood the test of time despite many newer oral anticoagulants in the current medical scenario. ${ }^{9}$ Warfarin carries significant risk of bleeding and interaction with several medications. ${ }^{10}$ It is reported that, only $62 \%-66 \%$ of the patients taking Warfarin achieve a therapeutic level. ${ }^{11}$ It is therefore mandatory to monitor the effect of warfarin on regular intervals. The female patients taking warfarin are likely to suffer from heavy menstrual bleeding (HMB). A study of 90 women, aged 15-49 years, reported that the abnormal uterine bleeding was reported by $17.8 \%$ women before use of anticoagulation therapy while $29.5 \%$ women reported this problem after the start of anticoagulants. ${ }^{12}$ The treatment of HMB is quite challenging and the efficacy of commonly used medicines like Tranexamic acid is not well established. ${ }^{13}$ The other pharmacological options include Levonorgestrel intrauterine system, high dose progestin-only therapy, and combined hormonal contraceptives. However, these treatments are associated with fears of thrombosis and the safety is not well established. Women who do not respond to medical treatment or who do not wish to retain their fertility may be considered for surgical management. ${ }^{14}$

While reporting the efficacy of any form of treatment it is necessary to use an objective method of quantification of abnormal uterine bleeding. So far there is no purely objective method to quantify the bleeding due to practical problems and hence a semi-objective approach is needed. Attempts to evolve this type of evaluation have led to development of Pictorial Bleeding Assessment Chart (PBAC). The PBAC is a tool widely used in research settings to quantify menstrual blood loss. A pictorial chart score of 100 or more has been shown to have a specificity and sensitivity of $80 \%$ when used as a diagnostic test for heavy menstrual bleeding. Huq et al. showed that $60 \%$ of women using warfarin have $\mathrm{HMB}$, with a longer duration of menstruation. ${ }^{15}$ Warner and colleagues found positive correlations between objective menorrhagia with passing clots more than 1.1 inches in diameter and changing pads more frequently than every three hours. ${ }^{16}$ The PBAC score has objective value as a total score more than 100 points per menstrual cycle have been shown to indicate $>80-\mathrm{mL}$ of blood loss. ${ }^{17-19}$

Our study is perhaps first of its kind in Pakistan which has examined the role of oral progesterone for treatment of abnormal uterine bleeding among women on warfarin. In this study, 54.1\% had continuous per vaginal bleeding, $38.8 \%$ had menorrhagia, $4.7 \%$ had inter-menstrualbleeding and $2.4 \%$ had menorrhagia along with polymenorrhea. The efficacy of norethisterone in our study has no doubts as it was found to reduce the PBAC scores across all sub groups and at all points of follow-up. It is interesting that the patients had $100 \%$ compliance during the study period. In fact, many women were extremely obliged as they never received that degree of attention from the medical community in past. However, it is premature to extrapolate that they would continue this treatment on long term basis. Similarly, no sides effects of progesterone therapy were reported in the study period. This again must be taken with caution because if this therapy is advised over the extended premenopausal period of young women, the side effect may turn out to be of significant clinical significance. The prolonged used of norethisterone is known to adversely affects the important lipoprotein risk factors for coronary heart disease as it decreases HDL cholesterol and increased LDL cholesterol levels..$^{20}$ Similarly, it is also known to have increased tendency of venous thrombosis. Nevertheless, it is still a satisfactory option to reduce the menopausal bleeding in patients with prosthetic valves.

Limitations of study: The study has the limitations of being non-randomized and without any placebo and blinding. Yet one can argue that all patients acted as their own controls hence it still carries a lot of significance.

\section{CONCLUSION}

The warfarin induced abnormal uterine bleeding can be controlled effectively and safely with low dose of oral progesterone. The patients show good compliance to this mode of treatment.

\section{Grant Support \& Financial Disclosures: None.}

\section{REFERENCES}

1. American College of Gynecology. Management of Acute Abnormal Uterine Bleeding in non Pregnant ReproductiveAged Women. [Online] Cited on: April 2017. Accessed on: February 18, 2019. Available from: https://www. acog.org/-/media/Committee-Opinions/Committee-onGynecologic-Practice/co557.pdf. 
2. Sampaio RO, Fae KC, Demarchi LM, Pomerantzeff PM, Aiello VD, Spina GS. Rheumatic heart disease: 15 years of clinical and immunological follow-up. Vasc health Risk Manag. 2007;3:1007-1017.

3. Rizvi S, Khan M, Kundi A, Marsh D, Samad A, Pasha O. Status of rheumatic heart disease in rural Pakistan. Heart. 2004;90:394-399. doi: 10.1136/hrt.2003.025981.

4. Gul A, Hafizullah M. Rheumatic heart disease in urban school children of Peshawar. J Postgrad Med Inst. 2011;23:337-340.

5. Sliwa K, Zilla P. Rheumatic heart disease: the tip of the iceberg. Circulation. 2012;125(25):3060-3062. doi: 10.1161/ CIRCULATIONAHA.112.114199.

6. Carapetis JR. Rheumatic heart disease in developing countries. N Engl J Med. 2007;357:439-441. doi: 10.1056/ NEJMp078039.

7. Marijon E, Mirabel M, Celermajer DS, Jouven X. Rheumatic heart disease. Lancet. 2012;379:953-964. doi: 10.1016/S01406736(11)61171-9.

8. Vahanian A, Baumgartner H, Bax J, Butchart E, Dion R, Filippatos G, et al. Guidelines on the management of valvular heart disease: the Task Force on the Management of Valvular Disease of the European Society of Cardiology. Eur Heart J. 2007;28(2):230-268. doi: 10.1093/eurheartj/ehl428.

9. Campbell HA, Roberts WL, Smith WK, Link KP. Studies on the hemorrhagic sweet clover disease. The preparation of hemorrhagic concentrates. J Biol Chem. 1940;136:47-55.

10. Fang MC, Go AS, Chang Y. Death and disability from Warfarin associated intracranial and extra cranial hemorrhages. Am J Med. 2007;120:700-705. doi: 10.1016/j amjmed.2006.07.034.

11. Matchar DB, Jacobson A, Dolor R. Effect of home testing of international normalized ratio on clinical events. $\mathrm{N}$ Engl J Med. 2010;363:1608-1620. doi: 10.1056/NEJMoa1002617.

12. Sjalander A, Friberg B, Svensson P, Stigendal I, Lethagen S. Menorrhagia and minor bleeding symptoms in women on oral anticoagulayion. J Thromb Thombolysis. 2007;24:39-41.

13. Devabhaktuni P, Thomas P, Kapadia A, Sridevi, Bhupatiraju, S. Menstrual Abnormalities and Gynaecological Problems in Women on Anticoagulant and Antiplatelet Therapy: Management Options. Open J Obstet Gynecol. 2017;7:581599. doi: 10.4236/ojog.2017.75061.
14. Boonyawat $\mathrm{K}, \mathrm{O}^{\prime}$ Brien $\mathrm{SH}$, Bates SM. How we treat heavy menstrual bleeding associated with anticoagulants. Blood. 2017;130(24):2603-2609. doi: 10.1182/blood-2017-07-797423.

15. Huq FY, Tvarkova K, Arfa A, Kadir RA. Menstrual problems and contraception in women of reproductive age receiving oral anticoagulation. Contraception. 2011;84:128-132. doi: 10.1016/j.contraception.2010.12.011.

16. Warner PE, Critchley HOD, Lumsden MA, CampbellBrown M, Douglas A, Murray GD. Menorrhagia I: Measured Blood Loss, Clinical Features, and Outcome in Women with Heavy Periods: A Survey with Follow-Up Data. Am J Obstet Gynecol. 2004;190:1216-1223. doi: 10.1016/j. ajog.2003.11.015.

17. Reid PC, Coker A, Coltart R. Assessment of Menstrual Blood Loss Using a Pictorial Chart: A Validation Study. Br J Obstet Gynaecol. 2000;107:320-322. doi: 10.1111/j.1471-0528.2000. tb13225.x.

18. Higham JM, O'Brien PM, Shaw RW. Assessment of Menstrual Blood Loss Using a Pictorial Chart. Br J Obstet Gynaecol. 1990;97:734-739. doi: 10.1111/j.1471-0528.1990. tb16249.x.

19. Janssen CA, Scholten PC, Heintz AP. A Simple Visual Assessment Technique to Discriminate between Menorrhagia and Normal Menstrual Blood Loss. Obstet Gynecol. 1995;85(6):977-982. doi: 10.1016/0029 7844(95)00062-V

20. Farish E, Fletcher CD, Hart DM, Kitchener H, Sharpe GL. A long-term study of the effects of norethisterone on lipoprotein metabolism in menopausal women. Clin Chim Acta. 1983;132:193-198. doi: 10.1016/0009-8981(83)90247-4.

\section{Author`s Contribution:}

SK: Conceived, designed, did statistical analysis \& prepared the first draft of manuscript.

SA: Helped in study design and manuscript review. AJ: Supervised the study, conducted analysis and did final review of manuscript.
Authors:

1. Shafaq Nadeem, FCPS (Gynecology \& Obstetrics), Department of Cardiac Surgery, The Clinic for Women with Cardiac Diseases,

2. Shahid Abbas, FCPS (Cardiology), Department of Cardiology,

3. Anjum Jalal FRCS, FCPS (Cardiac Surgery), FRCS-CTh, Department of Cardiac Surgery,

1-3: Faisalabad Institute of Cardiology, Faisalabad, Pakistan. 